\title{
CRESCIMENTO E TEORES DE BORO EM PLANTAS DE EUCALIPTO (Eucalyptus citriodora) CULTIVADAS EM DOIS LATOSSOLOS SOB INFLUÊNCIA DE DOSES DE BORO E DISPONIBILIDADE DE ÁGUA ${ }^{1}$
}

Sílvio Júnio Ramos², Valdemar Faquin ${ }^{3}$, Rose Myrian Alves Ferreira ${ }^{4}$, Josinaldo Lopes Araújo ${ }^{5}$ Janice $^{2}$ Guedes de Carvalho ${ }^{3}$

\begin{abstract}
RESUMO - Este trabalho objetivou avaliar o efeito da aplicação de doses de boro no crescimento de Eucalyptus citriodora em um Latossolo Vermelho-Escuro e um Latossolo Vermelho-Amarelo, submetidos a diferentes tensões hídricas. O experimento foi conduzido em casa de vegetação, no Departamento de Ciência do Solo da Universidade Federal de Lavras, em Lavras, MG, usando-se vasos com três $\mathrm{dm}^{3}$ de solo. Utilizou-se o delineamento experimental inteiramente casualizado, em esquema fatorial $5 \times 2 \times 2$, sendo cinco doses de $\mathrm{B}(0,00 ; 0,25 ; 0,75 ; 2,25$; e 6,25 $\mathrm{mg} \mathrm{kg}^{-1}$ ); e dois tipos de Latossolo: Latossolo Vermelho-Escuro (LE) e Latossolo Vermelho-Amarelo (LV) e duas tensões hídricas $(-0,033$ e -0,010 MPa), com quatro repetições. Os resultados indicaram que tanto o LV quanto o LE, nas suas condições naturais, não supriram as exigências de B em Eucalyptus citriodora. Contudo, os maiores incrementos na produção de matéria seca das plantas foram observados em baixas doses de B aplicadas. A umidade do solo é um fator importante no aproveitamento de B do solo pelo Eucalyptus citriodora.
\end{abstract}

Palavras-chave: Micronutriente, água no solo e deficiência de boro.

\section{GROWTH AND BORON CONTENTS IN EUCALYPTUS (Eucalyptus citriodora) GROWING IN TWO LATOSOLS UNDER THE INFLUENCE OF BORON RATES AND WATER AVAILABILITY}

\begin{abstract}
The present work was carried out to evaluate the effect of Boron rates on the growth of Eucalyptus citriodora in two Latosols, submitted to different water tensions. The experiment was carried out in a greenhouse at the Soil Science Department of the Federal University of Lavras-MG and it was arranged in a completely randomized design in a $5 \times 2 \times 2$ factorial scheme with four replications, five B rates $(0.0 ; 0.25 ; 0.75$; 2.25; and $6.25 \mathrm{mg} \mathrm{kg}^{-1}$ ) and two soils, Dark Red Latosol (LEr) and Red Yellow Latosol (LVm) with two moisture levels (-0.033 and -0.010 MPa). The results obtained showed that under natural conditions, neither LEr nor LVm was able to supply Eucalyptus citriodora the requirements for Boron. However, the highest increase in dry matter yield was obtained at low rates of Boron supplied. Soil moisture was an important factor in Boron uptake for eucalyptus plants.
\end{abstract}

Keywords: Micronutrient, soil water content and boron deficiency.

\footnotetext{
${ }^{1}$ Recebido em 20.09.2007 e aceito para publicação em 26.01.2009.

${ }^{2}$ Programa de Pós-Graduação em Ciência doSolo da Universidade Federal de Lavras (UFLA). E-mail: <silviojramos@ gmail.com>.

${ }^{3}$ Departamento de Ciência do Solo da UFLA. E-mail: <vafaquin@ufla.br>e <janicegc@ufla.br>.

${ }^{4}$ Instituto Brasileiro do Meio Ambiente e dos Recursos Naturais Renováveis (IBAMA). E-mail: <rose.myrian@ yahoo.com.br>.

${ }^{5}$ Centro deCiênciaeTecnologiaAgroalimentardaUniversidadeFederal deCampina Grande(UFCG).E-mail:<jhosinal_araujo@yahoo.com.br>
} 


\section{INTRODUÇÃO}

Os solos destinados aos plantios florestais são geralmente limitantes em alguns nutrientes como o P, o K e, principalmente, o B (GONÇALVES e VALERI, 2001). Em plantios de eucalipto, a deficiência de B tem sido comum, principalmente nos de Eucalyptus citriodora (SILVEIRA et al., 1998), manifestando-se, sobretudo, pela seca de ponteiro (OLIVA et al., 1989), que é um dos sintomas característicos da carência do micronutriente. Silveira et al. (2004) relataram que a frequência com que ocorre deficiência desse nutriente em plantações de eucalipto é maior do que, na maioria dos demais nutrientes, perdendo apenas para o $\mathrm{Ke}$ para o P. Sgarbi et al. (1999) observaram redução na incidência da seca do ponteiro de $35 \%$ em solo arenoso e de $45 \%$ em solo argiloso com aplicação de $2,2 \mathrm{~kg}$ ha $^{-1}$ de B na região de Três Marias, MG, local onde há extensas áreas cultivadas com a cultura e apresenta longos períodos de déficit hídrico durante o ano.

Embora o papel fisiológico desse nutriente ainda não esteja totalmente elucidado, sabe-se, entretanto, da sua importância na formação da parede celular, mais especificamente na síntese dos seus componentes, como a pectina, a celulose e a lignina (MARSCHNER, 1995; EPSTEIN e BLOOM, 2006), sendo também relacionado ao metabolismo ou à incorporação do cálcio na parede celular (CAKMAK et al., 1995). Assim, a deficiência em B causa muitas alterações anatômicas, fisiológicas e bioquímicas nas plantas, porém a maioria dessas mudanças provavelmente são decorrentes dos efeitos secundários da deficiência (SHELP, 1993).

A dose adequada de $\mathrm{B}$ a ser fornecida às plantas é uma das maiores preocupações nas adubações com esse micronutriente, em razão da estreita faixa entre o nível adequado e o tóxico para a maioria das plantas (FAQUIN, 2005), sendo esta faixa variável em função da textura do solo (FERREIRA, 1992). Embora nos solos mais argilosos os teores totais de B sejam mais elevados devido aos maiores teores de matéria orgânica, estes apresentam maiores requerimentos de $\mathrm{B}$ para uma mesma disponibilidade do nutriente, em comparação com solos mais arenosos, o que, segundo Elrashidi e O'Connor (1982), se deve à adsorção desse nutriente nos óxidos de $\mathrm{Fe}$ e Al, presentes em maiores concentrações em solos argilosos. Portanto, os maiores riscos para a ocorrência de toxidez de B, quando as aplicações excedem as necessidades das culturas, é maior em solos mais arenosos.
Outro aspecto importante relacionado diretamente com a disponibilidade de B para o eucalipto referese às condições hídricas do solo. A capacidade de adaptação a situações de déficit hídrico apresentada por algumas espécies desse gênero tem possibilitado que os plantios sejam implantados em áreas de cerrados, onde ocorrem longos períodos de seca (SILVEIRA et al.,1995). Esse fator é de grande relevância, uma vez que interfere no teor de B no solo e na sua disponibilidade para as plantas. Nesse sentido, o B tem como principal forma de transporte no solo até a superfície das raízes o fluxo de massa, que por sua vez é diretamente proporcional ao fluxo de água no solo, sendo, portanto, extremamente afetado pelas suas condições de umidade (REICHARDT, 1985). Dessa forma, sob condições de baixa disponibilidade de água, acentuam-se os problemas de carência de B nos plantios de eucalipto. Segundo Sakya et al. (2002), o estresse hídrico diminui a absorção de B e sua translocação para as folhas, levando a um aumento no requerimento desse nutriente pelas plantas.

Nesse contexto, o objetivo deste trabalho foi avaliar, em latossolos de diferentes texturas, o efeito da aplicação de níveis de $\mathrm{B}$ e de tensões hídricas no crescimento e teores de B em plantas de Eucalyptus citriodora.

\section{MATERIAL E MÉTODOS}

O experimento foi conduzido em casa de vegetação no Departamento de Ciência do Solo da Universidade Federal de Lavras. Utilizaram-se amostras de um Latossolo Vermelho-Escuro (LE), textura argilosa, originário do Município de Curvelo, MG, e de um Latossolo Vermelho-Amarelo (LV), textura média, originário do Município de Itumirim, MG. As amostras de cada solo foram coletadas na camada de $0-20 \mathrm{~cm}$, removendo-se toda a vegetação e restos orgânicos da superfície. Após secas ao ar, as amostras foram peneiradas em malha de $2 \mathrm{~mm}$, para a realização das análises químicas e físicas (Tabela 1).

Foram utilizadas sementes de Eucalyptus citriodora, obtidas da Cia. Agrícola e Florestal Santa Bárbara, lote $\mathrm{n}^{\circ} 167$, por ser uma espécie sensível à deficiência de $\mathrm{B}$ e indicada para áreas de clima subtropical com elevada seca estacional (GOLFARI, 1975).

Os tratamentos foram distribuídos em delineamento inteiramente casualizado, num esquema fatorial 5 x 2 x 2 , sendo cinco doses de B $(0,00 ; 0,25 ; 0,75 ; 2,25$; e $6,25 \mathrm{mg} \mathrm{kg}^{-1}$, na forma de ácido bórico $-\mathrm{H}_{3} \mathrm{BO}_{3}$ ); dois 
tipos de solos: Latossolo Vermelho-Escuro (LE) e Latossolo Vermelho-Amarelo (LV) e duas tensões hídricas correspondentes a -0,033 MPa e -0,010 MPa, obtidas através da curva de umidade característica de cada solo. Foram utilizadas quatro repetições, sendo cada parcela experimental constituída de uma planta por vaso, perfazendo um total de 80 parcelas. As plantas foram cultivadas em vasos com $3 \mathrm{dm}^{3} \mathrm{de}$ solo, as quais receberam a adubação básica de macronutrientes com $50 \mathrm{mg}$ de N, $240 \mathrm{mg}$ de P, $100 \mathrm{mg}$ de K e $20 \mathrm{mg}$ de S por $\mathrm{dm}^{3}$ de solo, utilizando-se as seguintes fontes: nitrato de amônio - $\mathrm{NH}_{4} \mathrm{NO}_{3}$ fosfato de potássio $\mathrm{KH}_{2} \mathrm{PO}_{4}$ fosfato de cálcio - $\mathrm{Ca}\left(\mathrm{H}_{2} \mathrm{PO}_{4}\right)_{2} \mathrm{H}_{2} \mathrm{O}$ e sulfato de amônio - $\left(\mathrm{NH}_{4}\right)_{2} \mathrm{SO}_{4}$. A adubação básica com micronutrientes consistiu-se na aplicação de $3 \mathrm{mg} \mathrm{Mn}$; 1,33 mg Cu; $5 \mathrm{mg}$ Fé; e $5 \mathrm{mg}$ de $\mathrm{Zn}$ por $\mathrm{dm}^{3}$, fornecidos na forma de cloreto de manganês $-\mathrm{MnCl}_{2} 4 \mathrm{H}_{2} \mathrm{O}$, sulfato de cobre $-\mathrm{CuSO}_{4} 5 \mathrm{H}_{2} \mathrm{O}$, sulfato de ferro $-\mathrm{FeSO}_{4} 7 \mathrm{H}_{2} \mathrm{O}$ (como Fe-EDTA) e sulfato de zinco $-\mathrm{ZnSO}_{4} 7 \mathrm{H}_{2} \mathrm{O}$.

Tabela 1 - Características químicas e físicas do Latossolo Vermelho-Escuro (LE) e Latossolo VermelhoAmarelo (LV) antes da aplicação dos tratamentos

Table 1 - Chemical and physical characteristics of Red-Dark Latosol (LE) and Red-Yellow Latosol (LVA) before the treatments

\begin{tabular}{|c|c|c|}
\hline Características & LE & LV \\
\hline pH em água & 4,9 & 5,1 \\
\hline$P\left(\mathrm{mg} \mathrm{dm}^{-3}\right)$ & 1,0 & 1,0 \\
\hline $\mathrm{K}^{+}\left(\mathrm{mg} \mathrm{dm}^{-3}\right)$ & 22,0 & 30,0 \\
\hline $\mathrm{Ca}^{2+}\left(\mathrm{cmol}_{\mathrm{c}} \mathrm{dm}^{-3}\right)$ & 0,4 & 0,3 \\
\hline $\mathrm{Mg}^{2+}\left(\mathrm{cmol}_{\mathrm{c}} \mathrm{dm}^{-3}\right)$ & 0,1 & 0,1 \\
\hline $\mathrm{Al}^{3+}\left(\mathrm{cmol}_{\mathrm{c}} \mathrm{dm}^{-3}\right)$ & 0,5 & 0,4 \\
\hline $\mathrm{H}+\mathrm{Al}\left(\mathrm{cmol}_{\mathrm{c}} \mathrm{dm}^{-3}\right)$ & 4,0 & 1,5 \\
\hline $\mathrm{SB}\left(\mathrm{cmol}_{\mathrm{c}} \mathrm{dm}^{-3}\right)$ & 0,6 & 0,5 \\
\hline (t) $\left(\mathrm{cmol}_{\mathrm{c}} \mathrm{dm}^{-3}\right)$ & 1,1 & 0,9 \\
\hline $\mathrm{m}(\%)$ & 47,0 & 46,0 \\
\hline $\mathrm{T}\left(\mathrm{cmol}_{\mathrm{c}} \mathrm{dm}{ }^{-3}\right)$ & 4,6 & 2,0 \\
\hline $\mathrm{V}(\%)$ & 12,0 & 24,0 \\
\hline $\operatorname{MOS}\left(\mathrm{g} \mathrm{dm}^{-3}\right)$ & 2,7 & 1,3 \\
\hline Enxofre $\left(\mathrm{mg} \mathrm{dm}^{-3}\right)$ & 0,66 & 6,9 \\
\hline $\mathrm{B}\left(\mathrm{mg} \mathrm{dm}^{-3}\right)$ & 0,14 & 0,10 \\
\hline $\mathrm{Fe}_{2} \mathrm{O}_{3}\left(\mathrm{~g} \mathrm{~kg}^{-1}\right)$ & 148 & 7,5 \\
\hline $\mathrm{Al}_{2} \mathrm{O}_{3}\left(\mathrm{~g} \mathrm{~kg}^{-1}\right)$ & 142 & 11,4 \\
\hline Areia $\left(\mathrm{g} \mathrm{kg}^{-1}\right)$ & 360 & 740 \\
\hline Silte $\left(\mathrm{g} \mathrm{kg}^{-1}\right)$ & 180 & 120 \\
\hline $\operatorname{Argila~}\left(\mathrm{g} \mathrm{kg}^{-1}\right)$ & 460 & 140 \\
\hline Densidade de partícula $\left(\mathrm{g} \mathrm{cm}^{-3}\right)$ & 2,70 & 2,56 \\
\hline Densidade do solo $\left(\mathrm{g} \mathrm{cm}^{-3}\right)$ & 1,02 & 1,32 \\
\hline
\end{tabular}

$\mathrm{Pe} \mathrm{K}$ - Extrator Mehlich I; Ca, Mg e Al - Extrator KCl 1 mol $\mathrm{L}^{-1} ; \mathrm{H}+\mathrm{Al}$ - Extrator SMP; SB - Soma de Bases; (t) - CTC efetiva; (T) - CTC potencial (a pH 7,0); V - saturação por bases; e m - saturação por alumínio. $\mathrm{MO}$ - oxidação $\mathrm{Na}_{2} \mathrm{Cr}_{2} \mathrm{O}_{7} 0,67 \mathrm{~mol} \mathrm{~L}^{-}$ ${ }^{1}+\mathrm{H}_{2} \mathrm{SO}_{4} 5 \mathrm{~mol} \mathrm{~L}^{-1}$ (EMBRAPA, 1999).
Aplicou-se também carbonato de magnésio $\mathrm{MgCO}_{3}$ para fornecimento de $\mathrm{Mg}$ para elevar seu teor até o nível crítico proposto por Barros et al. (1986). Em seguida, os solos nos vasos permaneceram incubados por 15 dias, com umidade correspondente à tensão de -0,010 MPa, obtida através da curva de umidade característica para cada solo e mantida através de pesagens diárias. Após o período de incubação dos solos, foram semeadas 10 sementes por vaso, sendo a umidade dos solos ainda mantida a -0,010 MPa. Nessa fase, os vasos foram protegidos com sombrite $50 \%$ até o desbaste, que ocorreu aos 35 dias após a semeadura, deixando-se uma planta por vaso.

Somente no desbaste é que foi aplicada a tensão hídrica do tratamento de -0,033 MPa, suspendendose a irrigação dos vasos do tratamento até que essa umidade fosse atingida, mantendo-a até o final do experimento, através de pesagens diárias. A adubação nitrogenada em cobertura foi realizada a partir de 60 dias após a semeadura a cada 10 dias na dosagem de $80 \mathrm{mg} \mathrm{dm}^{3}$. A adubação com $\mathrm{S}$ foi realizada juntamente com o N, em duas aplicações de 22,86 mg dm³ $\mathrm{muntamente}^{3}$ com a segunda e a quarta coberturas nitrogenadas. $\mathrm{O} F$ fo foi complementado no LV em $5 \mathrm{mg} \mathrm{dm}^{3}$ na forma de Fe-EDTA. Durante a condução do experimento, a umidade dos solos correspondentes as tensões -0,033 e -0,010 MPa foi rigorosamente controlada através de pesagens diárias do conjunto vaso-solo-planta, repondose o volume evapotranspirado com água desmineralizada.

As plantas permaneceram submetidas às tensões hídricas por 95 dias quando foram colhidas. Da fase de semeio à colheita totalizou, 140 dias. Na colheita, avaliou-se a altura das plantas a partir do coleto e, em seguida, foram separadas em folhas novas, folhas velhas, ramos e raízes, sendo cada parte colocada em estufa de circulação forçada de $\operatorname{ar}\left(65-70^{\circ} \mathrm{C}\right)$ até peso constante, para a obtenção da matéria seca da parte aérea (folhas novas + folhas velhas + ramos) e matéria seca das raízes. O material vegetal foi moído separadamente em moinho tipo Willey, para a determinação dos teores de B em cada parte da planta, conforme metodologia descrita por Jackson (1970), sendo as leituras realizadas em fotocolorímetro.

As variáveis obtidas foram submetidas à análise de variância, teste de médias (Tukey) para os fatores tipo de solos, tensão hídrica e regressão polinomial para o fator doses de B, a 5\%, utilizando o programa SISVAR $^{\circledR}$.

R. Árvore, Viçosa-MG, v.33, n.1, p.57-65, 2009 


\section{RESULTADOS E DISCUSSÃO}

A produção de matéria seca da parte aérea (MSPA), raízes (MSR) e matéria seca total (MST) das plantas foram afetadas significativamente pelas doses de B, tipos de solos e tensões hídricas. Para essas variáveis, houve interação significativa apenas para solo x tensões hídricas. Observa-se na Figura 1 que o efeito das doses de B sobre a produção de MSPA, MSR e MST apresentou ajuste raiz quadrada, mostrando aumento acentuado

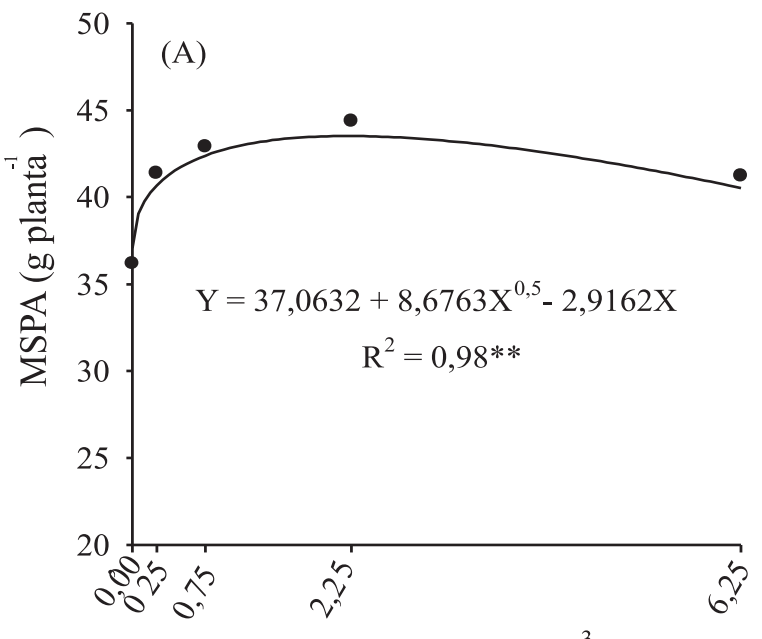

Doses de B $\left(\mathrm{mg} \mathrm{dm}^{-3}\right)$ na produção, quando se aplicaram pequenas doses de $\mathrm{B}$, independentemente do tipo de solo e das tensões hídricas a que foram submetidos. Curvas semelhantes foram obtidas por Sakya et al. (2002) para a produção de matéria seca de raízes e da parte aérea de Eucalyptus globulus submetidas a concentrações crescentes de B em solução nutritiva. Os efeitos da aplicação de B na produção de matéria seca do eucalipto também foram observados por Silveira et al. (1998), Silveira et al. (2000) e Sakya et al. (2002).

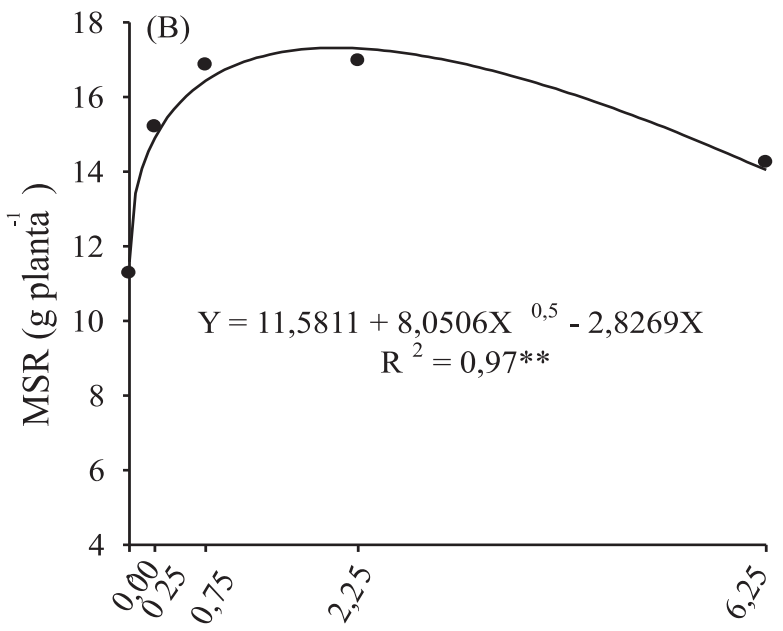

Doses de B (mg dm

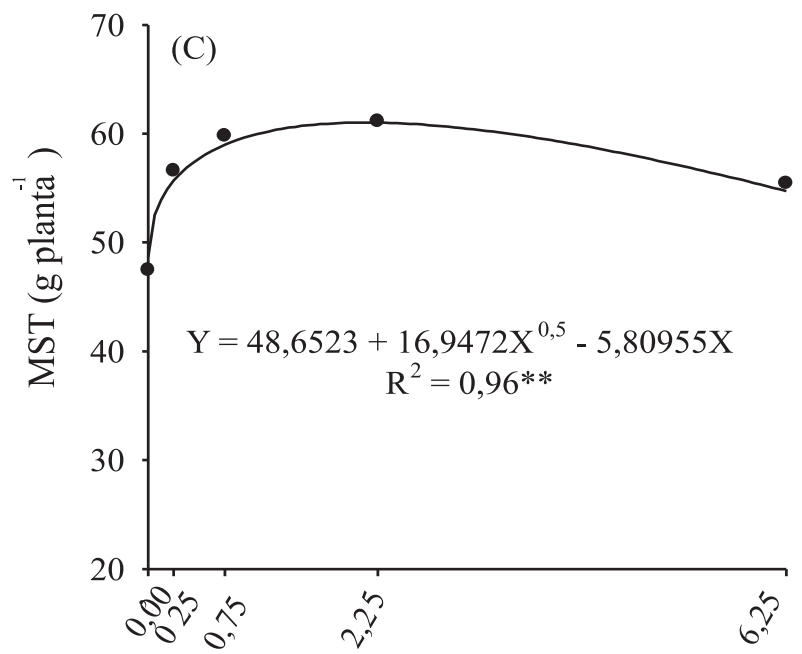

Doses de B (mg dm

Figura 1 - Produção de matéria seca da parte aérea (MSPA) (A), da raiz (MSR) (B) e total (MST) (C), em Eucalyptus citriodora aos 140 dias após o plantio, em função das doses de B. ** Significativo a $1 \%$.

Figure 1 - Dry yield of shoot $(A)$, root $(B)$ and total $(C)$ of Eucalyptus citriodora at 140 days after planting, in function of $B$ rates. ** Significantly at $1 \%$.

R. Árvore, Viçosa-MG, v.33, n.1, p.57-65, 2009 
Neste trabalho, a resposta encontrada na produção de matéria seca em plantas de Eucalyptus citriodora ao B aplicado é decorrente da sua baixa disponibilidade nos solos utilizados quando em condições naturais $\left(0,14\right.$ e $0,10 \mathrm{mg} \mathrm{dm}^{-3} \mathrm{de} B$ para LE e LV, respectivamente). Baseando-se nas interpretações de Abreu et al. (2007), os teores originais de B nos solos utilizados neste trabalho são classificados como baixos a muito baixos. As doses de $\mathrm{B}$ utilizadas que proporcionaram a máxima produção de matéria seca foram de 2,03; 2,21; e 2,13 $\mathrm{mg} \mathrm{dm}{ }^{-3} \mathrm{de}$ B para MSPA, MSR e MST, respectivamente. Entretanto, observou-se que na dose acima de 2,25 $\mathrm{mg} \mathrm{dm}^{-3}$ houve redução na produção de matéria seca das plantas, indicando o efeito tóxico do B. A maior parte do $\mathrm{B}$ adicionado ao solo, na faixa de $\mathrm{pH}$ da maioria dos solos agrícolas, permanece na forma neutra, a qual praticamente não interage com a fase sólida do solo, permanecendo em grande parte na solução como tal (COMMUNAR e KEREN, 2005). Como seu transporte até as raízes dá-se por fluxo de massa, a adição de doses de B além da necessidade da planta pode ter levado a um nível de toxidez, promovendo redução no seu crescimento.

O efeito da interação solo x umidade sobre a produção de matéria seca das plantas de eucalipto é apresentado na Figura 2. Verificou-se que a produção de MSPA, MSR e MST ixibiram o mesmo comportamento em razão das combinações de solo e tensões hídricas, independentemente das doses de B. De maneira geral, os maiores valores dessas variáveis foram obtidos no solo LV, sob maior disponibilidade de água (-0,010 MPa).
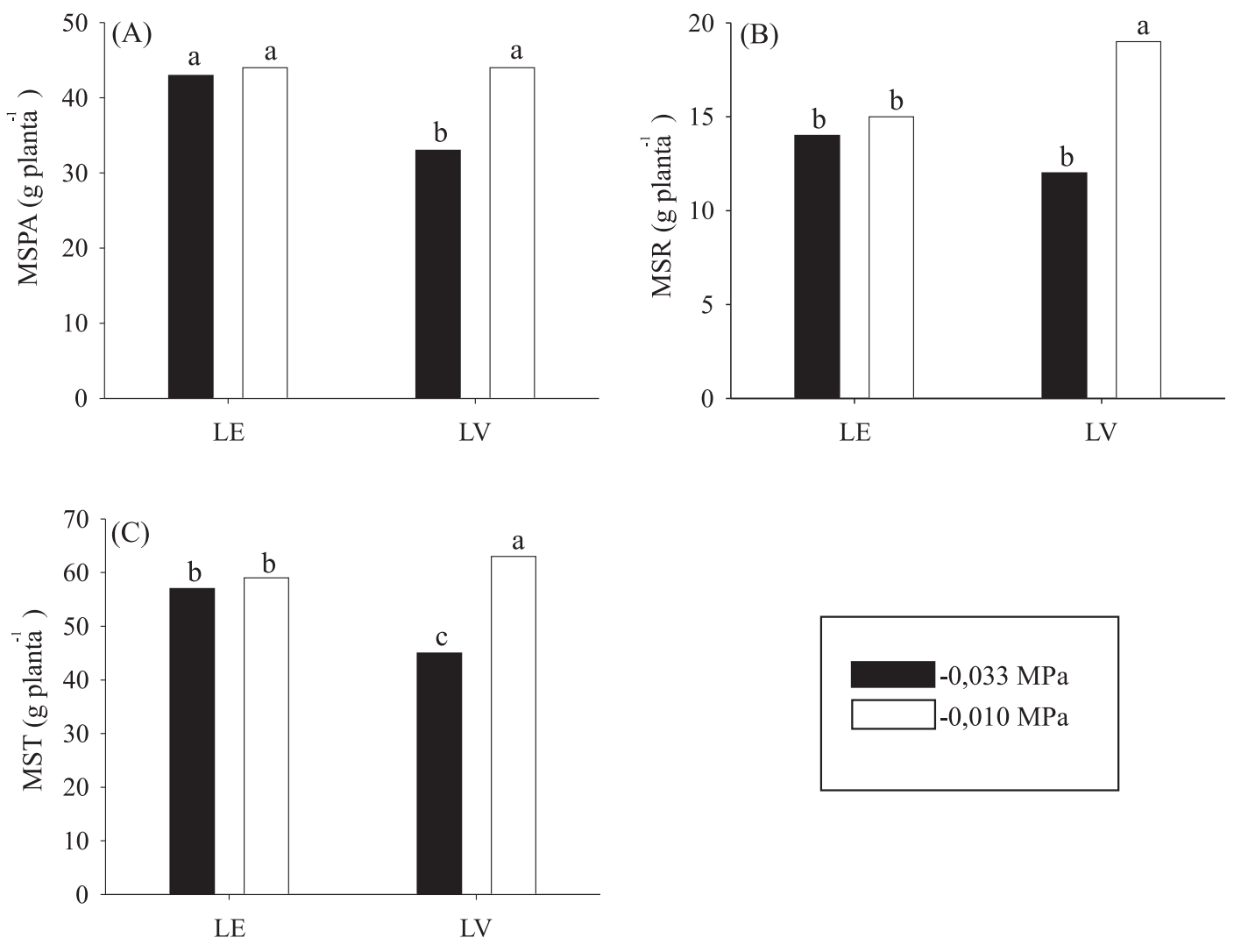

Figura 2 - Produção de matéria seca da parte aérea (MSPA) (A), raízes (MSR) (B) e total (MST) (C), em plantas de Eucalyptus citriodora aos 140 dias após o plantio, cultivada em dois latossolos (LE e LV) e submetida a duas tensões hídricas (-0,033 e -0,10 MPa). Médias seguidas de letras iguais não diferem entre si (Tukey 5\%).

Figure 2 - Dry yield of shoot $(A)$, root $(B)$ and total $(C)$ in Eucalyptus citriodora at 140 days after planting, grown in two latosols ( $L E$ and $L V)$ and two moisture levels (-0.033 and -0.010 MPa). Means with the same letter are not significantly different (Tukey $5 \%$ ). 
Observou-se que a umidade afetou o desenvolvimento das plantas, principalmente, no LV a -0,033 MPa (Figura 2). Isso se deve, provavelmente, ao elevado teor de areia (74\%) nesse solo. Solos mais arenosos sob condições não saturadas têm a sua condutividade hidráulica reduzida mais drasticamente do que nos solos argilosos (LIBARDI, 2005), o que se reflete em menor suprimento de boro para as plantas, pelo fato de este nutriente se movimentar no solo principalmente por fluxo de massa, que por sua vez é diretamente proporcional à condutividade hidráulica do solo. Quando as plantas foram cultivadas nesse solo a -0,033 MPa, sob baixas concentrações de B, as raízes apresentaram interrupção da elongação, tornando-se grossas e mais curtas. $\mathrm{O}$ crescimento celular é resultante dos processos de divisão celular e elongação, e, segundo Shelp (1993), o B é necessário para que ocorra ambos os processos e sua carência inibe o crescimento radicular. Marschner (1995) citou que uma das mais rápidas respostas à deficiência de $\mathrm{B}$ é a inibição ou interrupção da elongação das raízes. Grassi Filho (1995), trabalhando com três doses de boro $(0,5,1,5$ e 4,5 $\mathrm{mg} \mathrm{kg}^{-1}$ ) aplicadas em cova de plantio, observou diminuição no peso seco e no comprimento radicular na menor dose de boro testada.

A altura das plantas aos 140 dias após o plantio (Figura 3) não apresentou variação significativa em função das doses de B aplicadas, o que difere dos resultados obtidos por Silveira et al. (2000) e Maffeis et al. (2000), os quais constataram que a não-aplicação de B limitou significativamente o crescimento em altura em Eucalyptus citriodora. No entanto, Barros et al. (1981) não observaram efeito significativo da aplicação de B na altura em plantas de Eucalyptus citriodora, constatando até mesmo tendência de redução na altura das plantas com a aplicação de B. Dessa forma, a altura de plantas possivelmente não é um bom parâmetro para avaliar a resposta do eucalipto à aplicação de B.

O efeito da interação solo $x$ umidade para a altura de plantas seguiu a mesma tendência apresentada para a produção de matéria seca das diversas partes da planta, ou seja, a altura das plantas não variou ao se desenvolverem no LE submetido a diferentes tensões, enquanto no LV houve menor crescimento sob menor disponibilidade de água, independentemente das doses de B aplicadas (Figura 3). Os resultados observados corroboram as afirmações de Mengel e Kirby (2001) de que, quando uma tensão hídrica externa se traduz em déficit hídrico interno, ocorre uma série de mudanças fisiológicas e metabólicas, resultando, de imediato, na redução do crescimento.

Observou-se que, sob os teores de B nas condições naturais dos solos, os sintomas de deficiência desse nutriente nas plantas de Eucalyptus citriodora manifestaram-se de maneira definida, mas sua intensidade, bem como a época de surgimento, variou entre os solos utilizados, influenciados pelos níveis de umidade aos quais foram submetidos. A deficiência iniciou-se nos ponteiros das plantas, evoluindo para as partes inferiores. As folhas novas, de tamanho reduzido, tornaram-se coreáceas e enrugadas, cujas pontas enrolavam para baixo, com a evolução dos sintomas, e elas apresentaram uma clorose internerval, semelhante às descritas por Silveira et al. (2004). Os sintomas de toxidez, por sua vez, não foram bem identificados neste trabalho, pois, embora tenha ocorrido redução na produção de matéria seca nas diversas partes das plantas nas doses acima de $2,25 \mathrm{mg} \mathrm{dm}^{-3}$, apenas na dose de $6,25 \mathrm{mg} \mathrm{dm}^{-3}$ de B no LV a -0,010 MPa foi observada uma emissão de brotações que não se desenvolveram, manifestando-se aos 110 dias após a semeadura, não sendo, portanto, fator crítico para as plantas durante o experimento.

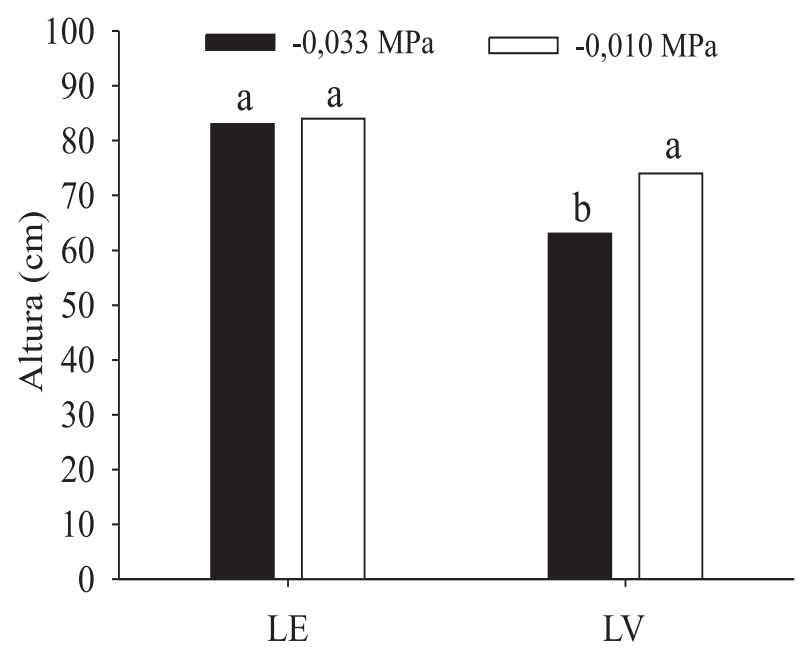

Figura 3 - Altura das plantas de Eucalyptus citriodora aos 140 dias após o plantio, cultivada em dois latossolos (LE e LV) e submetidas a duas tensões hídricas (-0,033 e -0,010 MPa). Médias seguidas da mesma letra não diferem entre si (Tukey $5 \%$ ).

Figure 3-Height of Eucalyptus citriodora, at 140 days after planting, grown in two latosols ( $L E$ and $L V$ ), under two moisture levels $(-0.033$ and $-0.010 \mathrm{MPa})$. Means with same letter are not significantly different (Tukey 5\%). 
Os teores de B nas diversas partes das plantas (Figura 4) foram afetados significativamente pelas doses de $\mathrm{B}$, pelas tensões hídricas e pela interação entre esses fatores. Os maiores teores desse nutriente foram observados nas folhas velhas. Nas folhas novas (Figura 4 a), os teores de B estiveram entre 8 e $64 \mathrm{mg} \mathrm{kg}^{-1}$, enquanto nas folhas velhas (Figura $4 \mathrm{~b}$ ) os valores variaram de 18 a $84 \mathrm{mg} \mathrm{kg}^{-1}$, em função dos tratamentos utilizados. Esses resultados concordam com os obtidos por Sgarbi et al. (1999) e por Asad et al. (2001), que observaram que o requerimento crítico de B aumentou com a idade da folha em plantas de Eucalyptus urophylla. De acordo com Mengel e Kirby (2001), devido à imobilidade do B no floema, sua translocação é quase que inexistente e, por tanto, seu teor é maior nas folhas mais velhas. O teor de B nas folhas novas (Figura 4a) e nas folhas velhas (Figura $4 b$ ) aumentou com a aplicação de doses crescentes de B, porém com diferentes repostas quando cultivadas em solos submetidos a diferentes tensões hídricas, como ocorrido na produção de matéria seca. No LE, independentemente das doses de B (média das doses de B), os teores não variaram em função das tensões hídricas, enquanto no LV os maiores teores de $\mathrm{B}$ foram proporcionados pela maior disponibilidade de água (-0,010 Mpa) em ambos os tipos de folha, concordando com os resultados obtidos por Pant et al. (1998) e Sakya et al. (2002). Assim, devido ao fato de o mecanismo principal de contato desse nutriente com a raiz ser o fluxo de massa, sob baixa disponibilidade de água, sua absorção é prejudicada (FAQUIN, 2005).
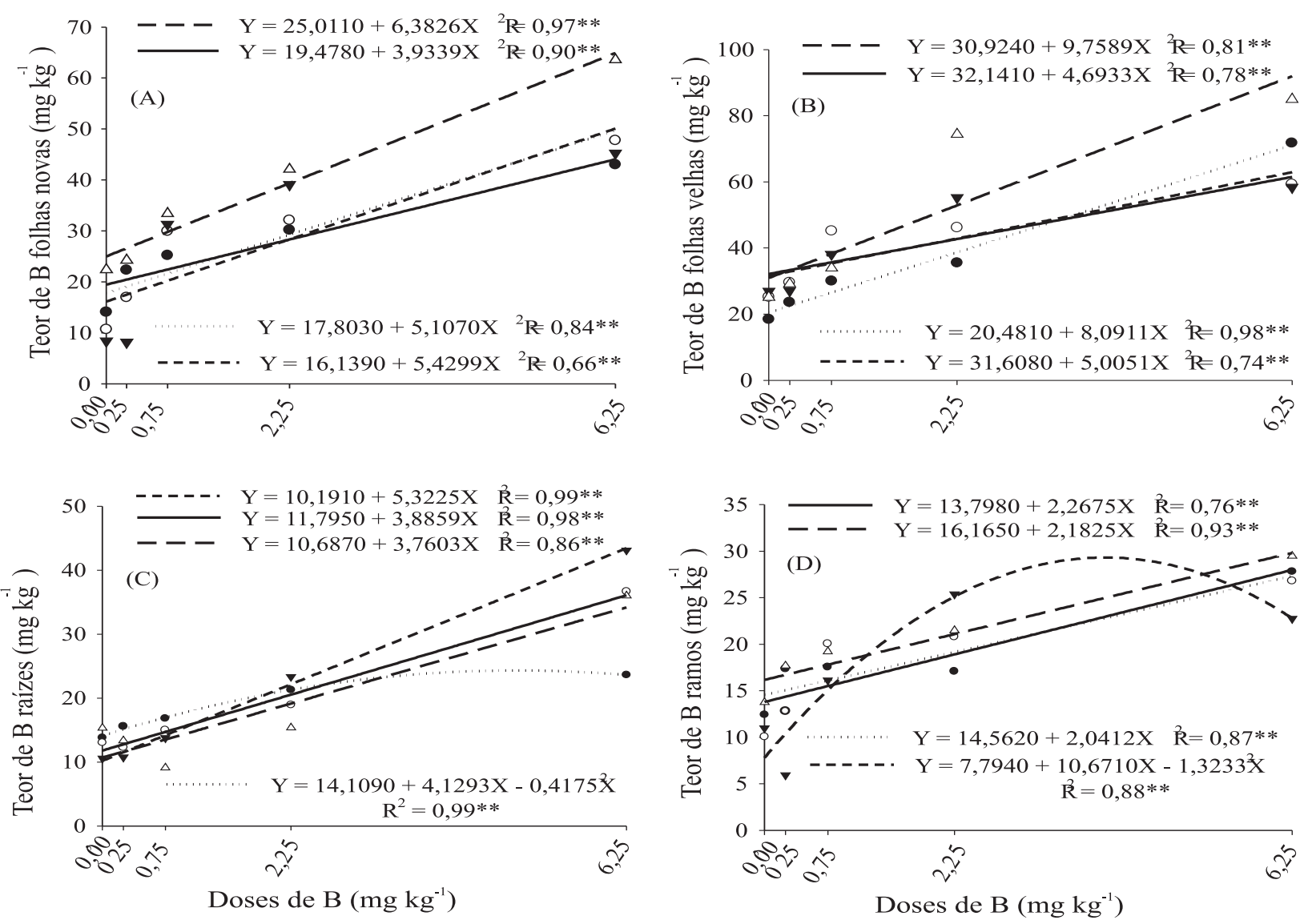

\begin{tabular}{lllllll}
$\Delta \quad \mathrm{LV}-0,010 \mathrm{MPa}$ & $\boldsymbol{\nabla}$ & $\mathrm{LV}-0,330 \mathrm{MPa}$ & $\circ$ & $\mathrm{LE}-0,010 \mathrm{MPa}$ & $\bullet$ & $\mathrm{LE}-0,330 \mathrm{MPa}$ \\
\hline
\end{tabular}

Figura 4 - Teor de B em folhas novas (A), em folhas velhas (B), nas raízes (C) e nos ramos (D) em Eucalyptus citriodora aos 140 dias após o plantio, em dois latossolos (LE e LV) e duas tensões hídricas $(-0,033$ e -0,010 MPa).

Figure 4 - Boron content in new leaves $(A)$, old leaves $(B)$, roots $(C)$ and stems $(D)$ of Eucalyptus citriodora, at 140 days after planting, in two latosols (LE and LV) and two moisture levels (-0.033 and -0.010,MPa). 
Nas raízes, com exceção do LE a -0,033 MPa, os teores de B aumentaram linearmente com a elevação das doses de B (Figura 4c). Entretanto, até a dose de $2,25 \mathrm{mg} \mathrm{dm}^{-3}$ ocorreu pequena variação entre as curvas dos diversos tratamentos. Acima dessa dose, observaramse maiores teores de B nas raízes no LV a -0,033 MPa. Independentemente das doses de B (média das doses), não houve variação significativa nos teores desse nutriente entre as tensões hídricas, embora no LV o maior valor observado tenha sido na tensão de $-0,033$ $\mathrm{MPa}$. Isso é um indicativo de que nesse solo houve maior acumulação de $\mathrm{B}$ nas raízes em detrimento de seu transporte para as folhas, em razão da menor disponibilidade de água. Porém, em solos arenosos sob condições não saturadas, sua condutividade hidráulica é ainda mais reduzida em relação aos solos argilosos. Assim, esse tratamento, independentemente das doses de B, foi o que proporcionou a menor produção de matéria seca nas plantas.

Nos ramos (Figura 4d), os teores de B, em média, foram cerca de duas vezes menor quando comparados com os das folhas velhas, concordando os resultados obtidos por Silveira et al. (1998) para essa espécie. No solo LV, a -0,033 MPa o ajuste em função das doses de $\mathrm{B}$ foi quadrático, enquanto nas demais combinações solo e umidade os teores de B aumentaram linearmente com o incremento das doses.

Embora, de maneira geral, os teores de B nas partes avaliadas das plantas tenham aumentado em função das doses crescentes desse nutriente, isso não se refletiu em aumentos na produção de matéria seca nas doses superiores a 2,09 $\mathrm{mg} \mathrm{dm}^{-3}$ no LE e 2,26 $\mathrm{mg} \mathrm{dm}^{-3}$ no LV, indicando um provável consumo de $\mathrm{B}$ além da necessidade da planta, tal como observado por Vanderlei (1984). É importante ressaltar também que, em média, os teores de B nas folhas do eucalipto foram sempre superiores no LV, especialmente quando este apresentou maior disponibilidade de água.

\section{CONCLUSÕES}

Os solos avaliados, nas suas condições naturais, não supriram as exigências de B do Eucalyptus citriodora.

Os maiores incrementos na produção de matéria seca das plantas foram observados nas menores doses de B.

A umidade do solo é fator importante no aproveitamento de B do solo pelo Eucalyptus citriodora.

\section{REFERÊNCIAS}

ABREU, C. A.; LOPES, A. S.; SANTOS, G. Micronutrientes. In: NOVAIS, R. F. et al. (Eds.) Fertilidade do solo. Viçosa, MG: Sociedade Brasileira de Ciência do Solo, 2007. p.645-736.

ASAD, A.; BELL, R. W.; DELL, B. A critical comparison of the external and internal boron requirements for contrasting species in boron buffered solution culture. Plant Soil, v.233, n.1, p.31-45, 2001.

BARROS, N. F.; NOVAIS, R. F.; NEVES, J. C. L. Níveis críticos de fósforo no solo para eucalipto. Informe Agropecuário, v.12, n.141, p.15-19, 1986.

BARROS, N. F. et al.. Produção de eucalipto em solos de cerrado em resposta a aplicação de NPK, B e Zn. Revista Árvore, v.5, n.1, p.90-103, 1981.

CAKMAK, I.; KURZ, H.; MARSCHNER, H. Shortterm effects of boron, germanium and high light intensity on membrane permeability in boron deficient leaves of sunflower. Physiologia Plantarum, v.95, n.1, p.11-18, 1995.

COMMUNAR, G.; KEREN, R. Equilibrium and Nonequilibrium Transport of Boron in Soil. Soil Science Society of America, v.69, n.22, p.311-317, 2005.

ELRASHIDI, M. A.; O'CONNOR, G. A. Boron sorption and desorption in soils. Soil Science Society of America Journal, v.46, n.1, p.27-31, 1982 .

EMPRESA BRASILEIRA DE PESQUISA AGROPECUÁRIA - EMBRAPA. Embrapa Solos, Embrapa Informática Agropecuária. Manual de análises químicas de solos, plantas e fertilizantes. Brasília: Embrapa. Comunicação para Transferência de Tecnologia, 1999. 370p.

EPSTEIN, E.; BLOOM, A. Nutrição mineral de plantas: Princípios e perspectivas. Londrina: Planta, 2006. 403p.

FAQUIN, V. Nutrição mineral de plantas. Lavras:UFLA/FAEPE, 2005. 183p. 
FERREIRA, L. Avaliação indireta da erodibilidade em solos com altos teores de ferro e aspectos relacionados à mineralogia e micromorfologia. 1992. 82f. (Mestrado em Agronomia) - Escola Superior de Lavras, Lavras, MG, 1992.

GOLFARI, L. Zoneamento ecológico do Estado de Minas Gerias para reflorestamento. Belo Horizonte, Centro de Pesquisa Florestal da Região do Cerrado, 1975. 65p.

GONÇALVES, J. L. M.; VALERI, S. V.

Micronutrientes para culturas: eucalipto e pinus. In: FERREIRA, M. E.et al. (Eds.).

Micronutrientes e elementos tóxicos na agricultura. Jaboticabal: CNPq/FAPESP/ POTAFOS, 2001.p.393- 423.

GRASSI FILHO, H. Adições de cálcio e boro influenciando características fenológicas e composição foliar do limoeiro Siciliano enxertado sobre dois portas enxertos. 1995. 77f. Tese (Doutorado em Agronomia) - Escola Superior de Agricultura “Luiz de Queiroz", Piracicaba, 1995.

JACKSON, M. L. Analice química de suelos. Barcelona: Omega, 1970. 662p.

LIB ARDI, P. L. Dinâmica da água no solo. São Paulo: EDUSP, 2005. 335p.

MAFFEIS, A. R.; SILVEIRA, R. L. V. A.; BRITO, J. O. Reflexos das deficiências de macronutrientes e boro no crescimento de plantas, produção e qualidade de óleo essencial em Eucalyptus citriodora. Scientia Forestalis, n.57, p.87-98, 2000.

MARSCHNER, H. Mineral nutrition of higher plants. London: Academic, 1995. 889p.

MENGEL, K.; KIRBY, E. A. Principles of plant nutrition. Bern: International Potash Institute, 2001. 687p.

OLIVA, M.A. et al. Seca de ponteiros em Eucalyptus camaldulensis Dehn em relação a estresse hídrico e nutrição mineral. Revista Árvore, v.13, n.1, p.19-33, 1989.

PANT, J.; REKARSEM, B.; NOPPAKOONWONG, R. Effect of water stress on the boron response of wheat genotypes under low boron field conditions. Plant Soil, v.202, n.2, p.193-200, 1998.
REICHARDT, K. Processos de transferência no sistema soloplanta-atmosfera. Campinas: Fundação Cargill, 1985. 466p.

SAKYA, A.T.; DELL, B.; HUANG, L. Boron requeriments for Eucalyptus globulus seedlings. Plant and Soil, v.246, n.1, p.87-95, 2002.

SGARBI, F. et al. Crescimento e produção de biomassa de clone de Eucalyptus grandis $\mathrm{x}$ Eucalyptus urophylla em condições de deficiência de macronutrientes, B e Zn. Scientia Forestalis, n.56, p.69-82, 1999.

SHELP, B. J. Physiology and biochemistry of boron in plants. In: GUPTA, U. C. Boron and its role in crop production. Boca Raton: CRC Press, 1993. p.53-85.

SILVEIRA, R. L. V. A. et al. Absorção e exportação de macronutrientes pelas brotações de Eucalyptus grandis e Eucalyptus saligna em jardim clonal. In: CONGRESSO BRASILEIRO DE CIÊNCIA DO SOLO, 25., 1995, Viçosa. Anais... Viçosa, MG: SBCS; UFV, 1995. p.845-847.

SILVEIRA, R. L. V. A. et al. Crescimento e estado nutricional de brotações de Eucalyptus citriodora sob doses de boro em solução nutritiva.

Scientia Forestalis, n.57, p.53-67, 2000.

SILVEIRA, R. L V.A. et al. Evaluation of the nutritional status of Eucalypts: visual and foliar diagnosis and their interpretation. In:

GONÇALVES, J. L. M.; BENEDETTI, V. Forest nutrition and fertilization. Piracicaba: IPEF, 2004. p.85-111.

SIVEIRA, R. L. V. A.; GONÇALVES, A. N.; KRÜNER, T. L. Estado nutricional de Eucalyptus citriodora Hook cultivado sob diferentes doses de boro e sua relação com a agressividade de Botryosphaeria ribis. Scientia Forestalis, n.53, p.57-70, 1998.

VANDERLEI, J. C. Boro em materiais de três solos do município de LavrasMG. 1984. 96f. Dissertação (Mestrado em Agronomia) - Escola Superior de Agricultura de Lavras, Lavras, 1984.

R. Árvore, Viçosa-MG, v.33, n.1, p.57-65, 2009 